\title{
El papel de la virtud cívica en el liberalismo igualitarista ${ }^{1}$
}

\section{The role of civic virtue in egalitarian liberalism}

\author{
JORDI TENA SÁNCHEZ
}

Universidad Autónoma de Barcelona

RESUMEN. Los críticos con el liberalismo igualitarista suelen sostener que la virtud cívica es un elemento indispensable para la realización y mantenimiento de bienes sociales como la justicia social o distributiva. Acostumbran a argumentar también que el liberalismo igualitarista desatiende la importancia de la virtud cívica y que, por tanto, los fines liberal igualitaristas o bien resultan inalcanzables, o bien no pueden ser mantenidos.

En este trabajo se parte de la premisa de que, efectivamente, la virtud cívica es un instrumento indispensable para la realización y mantenimiento de bienes sociales como la justicia distributiva. Pero se argumenta que el liberalismo igualitarista no tiene ningún problema en reconocer este hecho de modo que las críticas hacia el mismo en este sentido andan desencaminadas. El Estado liberal igualitarista debe promover todas aquellas virtudes cívicas que sean necesarias para alcanzar y/o estabilizar la justicia de la sociedad con el único límite que fija el respeto a la prioridad de lo correcto sobre lo bueno.

A lo largo del trabajo se exponen los conceptos rawlsianos de pluralismo razonable, consenso entrecruzado entre doctrinas comprehensivas razonables y de neutralidad del Estado, y se trata de aclarar cuál es el papel
Abstract. Critics with egalitarian liberalism usually maintain that civic virtue is an essential element for implementation and stability of social goods like social justice. They usually argue as well that egalitarian liberalism neglects the importance of civic virtue and that, as a consequence, egalitarian liberal goals are either unachievable or unstable.

In this paper I assume that civic virtue certainly is an essential element for implementation and stability of social goods like distributive justice. However, I argue that egalitarian liberalism has no problem to recognize this, so criticism in this sense is wrong. Egalitarian liberal state must promote each civic virtue necessary for achieving and/or stabilizing social justice with the only limit given by priority of right over good.

Throughout this paper I expose the rawlsian concepts of reasonable pluralism, overlapping consensus among reasonable comprehensive doctrines and neutrality of state, and I try to clarify the role of civic virtue in this theoretical framework.

1 El presente trabajo se ha beneficiado de los comentarios de José Antonio Noguera. Por otra parte, se ha beneficiado también del apoyo del Ministerio de Educación y Ciencia y del FEDER a través del proyecto I+D+i con referencia SEJ2006 00959/SOCI, y del apoyo del MICINN a través del proyecto I+D+i con referencia CSO2009-09890. 
de la virtud cívica dentro de ese entramado teórico.

Palabras clave: Liberalismo igualitarista, virtud cívica, pluralismo razonable, doctrina comprehensiva razonable, consenso entrecruzado, neutralidad, ideas del bien, vida buena.

Key words: Egalitarian liberalism, civic virtue, reasonable pluralism, reasonable comprehensive doctrine, overlapping consensus, neutrality, ideas of good, good life.

En mala situación se halla un país gobernado sólo por leyes, porque ocurren mil cosas no contempladas por las leyes.

(Dr. Johnson, citado en Pettit, 1999, p. 313)

Evidentemente, una sociedad de ciudadanos activos es posible que sea una condición fáctica para el surgimiento, o para la viabilidad de una sociedad libre (...). Pero no entra en su definición más de lo que lo hace su carácter democrático.

(VAN PARIJS, 1996, p. 37).

\section{Introducción}

Escribía Immanuel Kant, allá por las postrimerías del siglo XVIII, que

el problema del establecimiento del Estado tiene solución incluso para un pueblo de demonios (...) y el problema se formula así: ordenar una muchedumbre de seres racionales que, para su conservación, exigen conjuntamente leyes universales, aun cuando cada uno tienda en su interior a eludir la ley, y establecer su constitución de modo tal que, aunque sus sentimientos particulares sean opuestos, los contengan mutuamente de manera que el resultado de su conducta pública sea el mismo que si no tuvieran tales malas inclinaciones. (Immanuel Kant, 1795, 38: ss).

Mucho es lo que ha dado que hablar esta tesis desde entonces. En la interpretación más habitual de la misma, se sostiene que Kant supone que el orden social y, particularmente, la justicia de la sociedad son posibles sin virtud cívica y no deben depender de la misma. Tal vez pueda discutirse si esa es la interpretación más acertada de la tesis, pero no voy a entrar aquí en esa cuestión. Sostengo simplemente que esa es su interpretación habitual y por eso mismo me referiré a ella como la tesis de Kant.

Ciertos autores liberales han abrazado dicha tesis. Esto ha sido especialmente así en lo que, muy desafortunadamente desde mi punto de vista, ha venido a denominarse liberalismo «de derechas» o «libertariano».

Algunas precisiones conceptuales se hacen necesarias antes de poder seguir avanzando. En primer lugar, en estas páginas asumiré la distinción entre el liberalismo «libertariano» y el liberalismo «igualitarista». Algunos de los exponentes más destacables de la escuela libertariana serían F. Hayek o R. Nozik, mientras que entre los igualitaristas encontraríamos nombres como 
los de J. Rawls, R. Dworkin, A. Sen o P. Van Parijs. Yo en este trabajo me centraré en el liberalismo de corte igualitarista.

En segundo lugar, entenderé el concepto de justicia social o distributiva del modo en que lo hacen los liberales igualitaristas. Sin pretender entrar a escoger una propuesta concreta del relativamente amplio catálogo de teorías de la justicia de este tipo, para lo que aquí nos afecta, es suficiente con tener en cuenta que todas ellas combinan un profundo igualitarismo con un aún más profundo respeto por las libertades individuales. De hecho, se podría sostener que la tolerancia, entendida como el derecho del que todo individuo debe disfrutar para poder perseguir su propia concepción razonable del bien, constituye la base sobre la que se erige el edificio del liberalismo igualitarista.

Finalmente, por virtud cívica entenderé una motivación causalmente eficiente para actuar según lo requerido por la justicia social (Tena 2008).

Los críticos con el liberalismo, principalmente desde posturas republicanas, marxistas o comunitaristas aunque no exclusivamente ${ }^{2}$, suelen sostener un triple argumento. Por una parte mantienen que la tesis de Kant es falsa. En segundo lugar, atribuyen la postura kantiana al liberalismo en su conjunto, también al liberalismo igualitarista. Finalmente, derivado de lo anterior, sostienen que los fines liberal-igualitaristas, principalmente la justicia social, resultan imposibles de alcanzar y/o de mantener.

Vale la pena distinguir entre estas dos últimas cuestiones. La justicia podría ser, en primer lugar, imposible de alcanzar. Pero, aunque pudiese ser conquistada, también podría resultar imposible de sostener. En este segundo caso, las teorías liberales no cumplirían el desiderata de estabilidad (Domènech 1998). Desde este punto de vista, desde el mismo momento en que la justicia liberal quedara establecida, quedarían también establecidas las bases de su socavación.

Las críticas suelen dirigirse con especial ahínco contra la tesis de la neutralidad del Estado frente a las distintas doctrinas comprehensivas, concepciones del bien y concepciones de la vida buena razonables. Más adelante en estas páginas desarrollaré dicha tesis, por el momento me limito simplemente a apuntar que los críticos del liberalismo igualitarista acostumbran a argumentar que los liberales igualitaristas se encuentran presos entre cuernos de un dilema, en este sentido, los igualitaristas no tendrían más remedio que cometer violaciones puntuales del principio de neutralidad en aras de poder salvar al menos una parte de su ideal de justicia.

Yo coincido con los críticos del liberalismo en que la tesis de Kant es falsa, es decir, considero que sin virtud cívica no es posible alcanzar ni mantener un gran número de bienes sociales de primera magnitud, particularmente la

2 Véase, a modo de ejemplo, Bertomeu y Domènech (2005), G. Cohen (2001), Domènech (1989, 1996, 1998, 2003, 2004), Ovejero, Martí y Gargarella (2004), Pettit (1999, 2004), Sandel (2004) o Sunstein (2004). 
justicia de la sociedad. No sostengo que la virtud cívica sea constitutiva de la justicia o de otros bienes sociales. La virtud cívica no forma parte de la definición del concepto de justicia social. Sostengo, como veremos que suele hacerse en el liberalismo igualitarista, que la virtud cívica es una condición causal o empírica para la justicia y para otros bienes sociales, esto es, que es una condición necesaria para su realización efectiva.

La virtud cívica sería para la justicia lo que, por ejemplo, algunos autores suelen sostener que el desarrollo económico es para la democracia. Según estos autores, el desarrollo económico es una condición empírica necesaria pero no suficiente para que pueda surgir una democracia, para que ésta pueda realizarse de forma efectiva. Pero el desarrollo económico no forma parte de ninguna definición del concepto de democracia, no es constitutivo de la misma definicionalmente.

Tal y como se está sugiriendo, mi tesis en este punto es de naturaleza empírica y que como tal debería ser defendida. No obstante, no me voy a ocupar de esta cuestión en el presente trabajo, simplemente asumiré que se trata de una tesis cierta.

En segundo lugar, pienso que los críticos del liberalismo se encuentran básicamente equivocados por lo que se refiere a su interpretación de la versión igualitarista del mismo. De modo particular, sostendré que los exponentes más destacados de este liberalismo no asumen la tesis de Kant. Pese a que, como he dicho, éste será el tipo particular de liberalismo en el que me centraré en este trabajo, vale la pena destacar que, al menos desde mi punto de vista, tampoco hay nada en el liberalismo «libertariano» que lo haga incompatible con la virtud cívica o, más aún, que impida armar en torno a él una defensa de la virtud cívica del estilo de la del liberalismo igualitarista.

En estas páginas trataré de exponer la postura liberal igualitaria en lo referente a la virtud cívica. Para hacerlo, me basaré principal, aunque no únicamente, en el máximo exponente de este tipo de liberalismo, John Rawls. Presentaré primero los conceptos de pluralismo razonable, doctrinas comprehensivas razonables y de consenso entrecruzado para posteriormente referirme de forma más específica al papel de la virtud cívica dentro de ese marco más general. Sostendré que Estado liberal igualitarista, no sólo puede sino que se encuentra normativamente obligado a promover todas aquellas virtudes necesarias para alcanzar y estabilizar la justicia de la sociedad. El único límite que debe respetar el Estado en la promoción de la virtud es el que viene dado por la prioridad de lo correcto sobre lo bueno. 


\section{El pluralismo razonable de las sociedades libres}

El pluralismo razonable es un fenómeno normal, inevitable y positivo que caracteriza a las sociedades libres ${ }^{3}$. El mismo ideal de lo que representa una sociedad libre tal y como la concebimos se basa en la constatación del hecho de que la gente discrepa razonable y profundamente acerca de lo que constituye la vida buena, la vida que merece la pena ser vivida, y de que su libertad consiste, precisamente, en poder perseguir dicho ideal ${ }^{4}$. En este sentido, el único medio para mantener a una sociedad unida en torno a una serie de concepciones de la vida buena es el uso ilegítimo de medios tales como el poder represivo del Estado o la violencia sectaria.

Siguiendo a Rawls $(1996,2002)$ entenderé por pluralismo el hecho de que, en una misma sociedad exista una gran variedad de doctrinas comprehensivas que incluyen, entre otras cosas, diferentes ideas del bien y de la virtud o de la vida buena. Dichas doctrinas son contradictorias e irreconciliables entre sí. En el pluralismo simple, dichas doctrinas existen como un hecho de facto pero éstas y las personas que las albergan no son, mayoritariamente, ni tolerantes ni razonables y los diferentes grupos tratan de imponer su concepción a los demás por medios ilícitos. Esta era, por ejemplo, la situación en la Europa de las guerras de religión o es la de la mayoría de los países árabes en la actualidad. Por el contrario, se da pluralismo razonable cuando las doctrinas comprehensivas existentes en la sociedad (o las más importantes) son razonables y aceptan y asumen el principio de tolerancia. En una situación así las personas pueden albergar una determinada doctrina comprehensiva pero saben que puede haber, y que hay de hecho, otras personas también razonables que no comparten su doctrina y que tienen argumentos razonables para no hacerlo. Las personas razonables aceptan y valoran positivamente esa situación y no tratan de imponer sus ideas por medios ilegítimos. Existe pluralismo razonable cuando las personas que albergan doctrinas comprehensivas distintas se ponen de acuerdo y apoyan efectivamente un marco común y equitativo de convivencia que incluya cosas como unas instituciones y reglas del juego que permitan a todos perseguir libremente sus ideales razonables de la vida buena.

También siguiendo a Rawls $(1996,2002)$, por doctrinas comprehensivas 5 entenderé una concepción moral general que incluye ideales acerca de lo que es una vida buena, acerca del carácter de la persona, de las relaciones sociales y familiares y, en el límite, cuando hablamos de doctrinas plenamente comprehensivas, esos ideales abarcan la globalidad de nuestra vida. Religiones

3 J. Cohen (2001); Habermas (2001); Rawls (1979, 1996, 2002); Van Parijs (1996).

${ }^{4}$ Rawls (1979, 1996, 2002); Van Parijs (1996).

5 J. Cohen (2001), en una formulación muy similar, se refiere a «filosofías de vida», etiqueta que, probablemente, resulta más afortunada para una comprensión intuitiva del concepto. 
como el cristianismo o el Islam, ideologías como el comunismo, el anarquismo o el liberalismo clásico de autores como Kant o Mill o las formas de nacionalismo más identitario constituyen ejemplos de este tipo de doctrinas comprehensivas.

Nuevamente, dichas doctrinas son razonables cuando aceptan realmente (no de modo puramente táctico) el hecho del pluralismo y no tratan de imponerse de forma ilícita. El florecimiento de tales doctrinas es un hecho normal de la vida humana. Son principalmente productos de nuestra razón teórica aplicada a asuntos de vital importancia para nosotros (como el sentido de nuestra existencia). En tanto que productos de la razón teórica y dada la complejidad de los temas tratados, no podemos esperar que se alcance un acuerdo racional entre personas razonables; es por este motivo que el pluralismo es un hecho inevitable, constitutivo de nuestra naturaleza ${ }^{6}$. Debemos aceptar, por tanto, el principio postmetafísico según el cual la vida buena, a diferencia de la justicia, no puede ser materia de acuerdo racional (Habermas 2001; Van Parijs 1993).

Nótese que la razonabilidad de una doctrina comprehensiva no nos dice nada acerca de su veracidad. Las diferentes doctrinas comprehensivas son incompatibles entre sí de modo que no pueden ser todas verdaderas y probablemente ninguna lo sea. Puede que las personas que albergan una determinada doctrina comprehensiva irrazonable estén en posesión de la verdad. Puede que, por ejemplo, Ben Laden tenga razón y su interpretación del Corán sea la correcta de modo que todos los que no creemos en Alá tengamos asegurada la condena eterna. Sin embargo, Ben Laden debería aceptar, si fuese razonable, que existen razones que personas razonables pueden esgrimir para no aceptar esa doctrina y que esas personas gozan de libertad para escoger su propio camino, aunque dicho camino sea el camino de la condena eterna, porque la libertad es libertad para escoger el bien o el mal. En este sentido, lo correcto goza de prioridad sobre lo bueno (Rawls 1996, 2002; Van Parijs 1993).

Siendo, como se ha comentado, principalmente productos de la razón teórica, las doctrinas comprehensivas son también resultado de la razón práctica en un determinado sentido. Las condiciones de la realidad social en la que se desarrollan influirán sobre dichas doctrinas (Rawls 1996, 2002). Esto no es sorprendente, al fin y al cabo, lo único que se afirma es que las condiciones de la realidad social influyen sobre las creencias de los individuos. En este sentido, es de esperar que el normal funcionamiento de las instituciones de una sociedad libre influya sobre las doctrinas comprehensivas de manera que éstas se vayan tornando razonables. ${ }^{7}$ Pese a esto, siempre habrá ciudadanos

6 Arnsperger y Van Parijs (2002); Habermas (2001); Rawls (1996, 2002); Van Parijs (1993, 1996).

7 No voy a entrar aquí a desarrollar el mecanismo concreto a través del cual Rawls sostiene que cabe esperar que doctrinas que no son razonables lo acaben siendo. Puede encontrarse dicha explicación en Rawls (2002) o, de forma más detallada, en Rawls (1996). 
que alberguen doctrinas comprehensivas que no sean razonables, que sean intolerantes e incluso violentas. Nos hallamos aquí con la cuestión clásica de la tolerancia con los intolerantes. Para estos casos Rawls prescribe la regla lockeana del peligro claro e inminente (Rawls 1996). A saber, el intolerante debe ver respetados sus derechos más básicos como la libertad de expresión política. Tales derechos sólo le pueden ser conculcados en una situación de peligro claro e inminente, cuando se produce una crisis constitucional de un tipo tal que las instituciones políticas no pueden operar correctamente o no pueden tomar las medidas necesarias para asegurar su propia existencia.

La mayoría de las personas empero no suele albergar doctrinas plenamente comprehensivas, ni tan sólo de tipo razonable. Más bien, su forma de ver el mundo incluye creencias derivadas de distintas doctrinas comprehensivas diferentes. Este hecho hace más fácil que los ciudadanos con concepciones dispares de lo que constituye la vida buena, aquella vida que merece la pena ser vivida, puedan llegar a ponerse de acuerdo en torno a unos principios de justicia que regulen la convivencia. Volveré sobre esta cuestión más adelante.

Pese a que no podemos estar seguros de que nuestra doctrina comprehensiva sea verdadera y probablemente sea errónea en una importante medida, no podemos imaginar un mundo en el que las personas no alberguen doctrinas siquiera parcialmente comprehensivas. Dichas doctrinas incluyen ideas acerca del bien y de la vida buena, incluyen por tanto los fines de nuestro proyecto de vida. Sin ellas nuestra existencia no tendría sentido, ni tan sólo sabríamos qué hacer porque no podríamos fijarnos objetivos (Rawls 1996, 2002, 2002b).

En síntesis, en una sociedad libre las personas albergan ideas totalmente dispares y hasta contradictorias sobre lo que es una vida buena, una vida que merece la pena ser vivida. Si dichas concepciones son razonables, el Estado tiene la obligación de respetarlas y, más aún, de proporcionarles a los ciudadanos medios para que puedan hacer realidad sus ideales en la medida de lo posible.

La neutralidad del Estado frente a las doctrinas comprehensivas, concepciones del bien y concepciones de la vida buena razonables

Del hecho del pluralismo razonable se deriva la obligación del Estado de mostrarse neutral entre las diferentes doctrinas comprehensivas y concepciones del bien y la vida buena que sean razonables. El Estado no puede, como principio general, hacer nada que vaya deliberadamente en contra de una determinada doctrina comprehensiva o que favorezca a otra por encima de las demás.

Pero que el Estado deba ser neutral frente a las distintas doctrinas comprehensivas puede querer decir muchas cosas y no todas ellas son correctas (Rawls 1996, 2002). 
Podríamos entender que nos estamos refiriendo a una neutralidad meramente procedimental. Se trataría de encontrar un procedimiento que regule la vida en común que pueda ser justificado sin recurrir a valores morales o, dado que esto parece imposible, que pueda sostenerse únicamente a partir de valores éticamente neutrales como la imparcialidad o la consistencia. Pero no es este el sentido en que el Estado debe ser neutral. Los principios que rigen la vida en común en una sociedad libre son principios de justicia substantivos. La neutralidad es neutralidad de propósitos de la acción política. Pero esto continúa pudiendo querer significar cosas distintas. Puede significar que el Estado debe abstenerse de cualquier actividad que aumente la probabilidad de que los ciudadanos apoyen a una doctrina comprehensiva en lugar de a otra (o que, como mínimo, establezca medidas compensatorias si lo hace). Éste no es tampoco el sentido en el que el Estado debe mantenerse neutral. La acción estatal tiene importantes y dispares efectos sobre las doctrinas comprehensivas. Tales efectos son normalmente imposibles de evitar y no suponen ningún tipo de injusticia o de parcialidad de la acción estatal.

Ilustraré la cuestión con un ejemplo. La globalización cultural y el hecho de poder consumir diferentes estilos musicales en cualquier parte del mundo pueden poner en peligro, y de hecho lo hacen, a los estilos musicales tradicionales autóctonos de Cataluña. Algunos de ellos, como la rumba catalana, parecen estar siendo capaces de adaptarse a los nuevos tiempos y estilos pero, sin embargo, otros, como el tradicional baile de la sardana, parecen irremediablemente condenados a la desaparición. Que la sardana desapareciese podría ser considerado un hecho lamentable desde el punto de vista del empobrecimiento cultural que tal acontecimiento representaría, pero no podría ser considerado injusto. Teniendo en cuenta que la justicia no tiene por qué ser la única preocupación del Estado en una sociedad libre (aunque sí la más importante), podría ser deseable que el gobierno de la Generalitat tomase medidas positivas, como de hecho ya hace, para promover la sardana (puede incluso que tales medidas puedan ser justificadas en términos de justicia aunque esto no es imprescindible). Pero, pese a todo, puede que tales medidas no tengan éxito y la sardana termine desapareciendo de todas formas. En una primera visión optimista sobre la cuestión, Rawls (1979) pensaba que en una sociedad libre sólo las prácticas o creencias socialmente negativas se verían condenadas a la desaparición. Posteriormente (1996), sin embargo, él mismo se percató de lo ingenuo de su postura, rectificó su planteamiento y asumió la tesis de Berlin (2004) según la cual no hay mundo social sin pérdida. En el mundo social hay espacio para muchos valores pero no para todos los que pueden existir. Muchos de esos valores chocan entre sí. Estamos condenados a elegir y al hacerlo renunciamos a algunos de esos valores por positivos que puedan ser.

$\mathrm{Si}$, continuando con mi ejemplo, ésta fuese la situación de la sardana, sólo habría una forma de salvarla de la desaparición, a saber, el uso ilegítimo del poder del Estado. El gobierno podría, por ejemplo, establecer algún tipo de 
censura que prohibiese el consumo de estilos musicales foráneos y/o modernos, o podría obligar a los ciudadanos a participar en ballades de sardanas para acceder a determinados derechos sociales. Si el gobierno actuase así, cosa que evidentemente no hace, no estaría siendo neutral y estaría restringiendo los derechos y libertades de los ciudadanos de forma ilegítima, incurriendo de tal modo en una injusticia.

Otro punto de vista sobre lo que debe significar la neutralidad del Estado puede consistir en que el Estado debe garantizar a los ciudadanos iguales oportunidades para perseguir cualquier concepción razonable del bien. Éste es ya un sentido aceptable de lo que significa que el Estado se debe mantener neutral. Yo mismo he afirmado algo similar en el último párrafo de la sección anterior. No obstante, habría que matizar qué se entiende aquí por iguales oportunidades. No voy a entrar en detalle en esta cuestión pero, obviamente, el Estado no tiene por qué garantizarle a alguien la satisfacción de unos gustos extremadamente caros o extravagantes o el disfrute de alguna actividad para la que no está capacitado o cosas por el estilo.

El sentido más preciso en el que el Estado se debe mantener neutral es el de que debe abstenerse de llevar a cabo actividades con la finalidad de promover una determinada doctrina comprehensiva en detrimento de otras o de prestar más asistencia a quienes la abracen o, a la inversa, debe también, obviamente, abstenerse de perjudicar deliberadamente a los que abracen una determinada doctrina comprehensiva. ${ }^{8}$

\section{El privilegio de la justicia social}

En mi argumentación hasta el momento vengo utilizando el término sociedad libre como sinónimo de sociedad justa y mantengo en todo momento dicha justicia como el objetivo a alcanzar y como el referente a la luz del cual juzgar la actuación del Estado. En este sentido he venido sosteniendo que en una sociedad justa debe darse el hecho del pluralismo razonable que es constitutivo de la misma y que el Estado debe mantenerse neutral ante las distintas concepciones razonables de la vida buena si no quiere socavar la justicia de la sociedad.

En este punto el lector podría preguntarse por la razón de otorgar un papel tan preeminente a la justicia social. ¿Por qué otorgar más importancia a ese bien que a otros como, por ejemplo, el crecimiento económico, la preservación de la identidad nacional o la promoción de la virtud? La respuesta a esta pregunta se encuentra ya contenida en lo que he dicho hasta el momento pero pienso que vale la pena que la explicite brevemente antes de continuar.

8 Arnsperger y Van Parijs (2002); Kymlicka (2004); Patten (2004); Rawls (1996, 2002); Van Parijs $(1993,1996)$. 
La justicia social o distributiva se refiere al reparto de los beneficios y las cargas, de los derechos y los deberes, entre los miembros de una sociedad ${ }^{9}$. El lugar privilegiado de la justicia social se debe a que dar respuesta al tipo de problemas que a ella incumben es más importante que responder a otras cuestiones éticas como las relativas a lo que es una sociedad buena o a preocupaciones de otro tipo como el crecimiento económico. Que la justicia es más importante que otras cuestiones éticas se deriva también de lo afirmado hasta el momento. Si bien cada uno de nosotros puede determinar fácilmente cuál es su particular concepción de la vida buena, que es lo importante para su propia existencia, esto sólo puede llevarse a cabo en el marco de instituciones que regulan y hacen compatible que todos podamos hacer lo mismo de un modo razonable. Dichas instituciones han de ser aceptadas por todos y su principal virtud para tal efecto debe consistir en que sean justas (Arnsperger y Van Parijs 2002). Nuevamente, por tanto, vemos que lo correcto goza de prioridad sobre lo bueno.

La justicia también goza de prioridad sobre otros fines sociales en tanto en cuanto constituye un bien social de primera magnitud y como tal es reconocido (Rawls 1996, 2002). Una sociedad buena no es reducible sin más a una sociedad justa, puede haber otros fines sociales valiosos. No obstante, no está claro en qué salimos beneficiados si nos apartamos de lo dictado por el igual respeto y la igual consideración ${ }^{10}$ (Arnsperger y Van Parijs 2002; Van Parijs 1993, 1996). Desde una perspectiva liberal igualitarista, la justicia es la primera virtud de las instituciones sociales (Rawls 1996, 2002) y haremos bien en ceñirnos a lo dictado por ella en la persecución de otros fines valiosos.

\section{El papel de la virtud cívica y de las ideas del bien en una sociedad libre}

Con lo que se ha dicho hasta el momento, podríamos estar tentados de preguntarnos si no tenían razón los críticos del liberalismo igualitarista al sostener que éste no contempla ningún papel para la virtud cívica. Pero, tal y como se advirtió en la introducción, dicho punto de vista es erróneo. A lo largo de esta sección trataré de mostrar de qué modo el Estado, no sólo puede sino que está normativamente obligado a promover la virtud cívica.

9 Arnsperger y Van Parijs (2002); Rawls (1979, 1996, 2002); Van Parijs (1996).

10 La prioridad de la justicia es aquí una cuestión de grado. Para Rawls (1996) no resulta admisible en ningún caso sacrificar parte de la justicia de la sociedad en aras de otros objetivos como pueda ser el crecimiento económico o la cohesión social. En cambio Van Parijs (1996) asume una concepción más laxa de esta tesis y acepta que grandes beneficios en término de algún otro bien pueden justificar pequeñas pérdidas en términos de justicia. Quedaría no obstante por determinar que es lo que consideramos como grandes beneficios y como pequeñas pérdidas. 


\section{Las ideas del bien}

Abordaré en primer lugar la cuestión más general de las ideas del bien. La tesis de la neutralidad del Estado no supone que una concepción política de la justicia no pueda incluir ideas del bien, tal cosa sería imposible (Rawls 1996, 2002). Una concepción política liberal de la justicia incluye diversas ideas del bien. Me referiré aquí a la concepción de Rawls ${ }^{11}$. En primer lugar, el bien se incluye en la concepción rawlsiana en tanto en cuanto se adopta una concepción filosófica de la persona en la que se concibe a ésta como capaz de albergar ideas del bien, así como una concepción plena y coherente de lo que es la vida buena y de perseguirla a lo largo de un ciclo vital completo. A esto se refiere el concepto de Rawls de bondad como racionalidad (Rawls 1996, 2002, 2002b). En segundo lugar, la teoría de la justicia de Rawls incluye una lista de bienes primarios. Los bienes primarios consisten en aquellos bienes básicos que los ciudadanos necesitarán para poder perseguir su ideal razonable de la vida buena independientemente de la forma específica que adopte éste. Rawls reformuló en diversas ocasiones los contenidos concretos de dicha lista en respuesta a las críticas recibidas por su primera formulación. Dicha lista incluye los derechos y libertades básicos de las personas, la libertad de movimientos y la libre elección de empleo en un marco de oportunidades variadas, poderes y prerrogativas de cargos y posiciones de responsabilidad en las instituciones políticas y económicas de la estructura básica de la sociedad ${ }^{12}$, los ingresos y la riqueza y las bases sociales del autorrespeto (Rawls 1996). En tercer lugar, tal y como he apuntado en la anterior sección, la sociedad política justa constituye en sí misma un bien de primera magnitud ${ }^{13}$. Finalmente, la última forma en que las ideas del bien se encuentran incluidas en una teoría de la justicia se refiere al papel de la virtud dentro de la misma, un tema muy importante en el presente trabajo, a continuación me referiré a esta cuestión. Antes empero es necesario puntualizar qué limitaciones debe cumplir la utilización de ideas del bien. Las ideas del bien que se utilicen deben ser inde-

11 Vale la pena hacer notar que me refiero a la postura más definitiva de Rawls, tal y como la formula en El liberalismo político y La justicia como equidad. Puede entenderse que en esas obras contemplamos a un «segundo Rawls» (Noguera 2003) en contraposición al Rawls más ambiguo en esta materia de la Teoría de la Justicia. También Van Parijs (1993) habla de la existencia de dos Rawls diferentes aunque en ese caso se refiere a la concepción del valor atribuido a las libertades básicas iguales. Supongo que podría hablarse de «dos Rawls» en muchos sentidos distintos. Teoría de la justicia fue una obra de una profundidad y un alcance temático impresionantes que revolucionó la filosofía política del siglo veinte pero que, obviamente, tuvo que ser sometida a importantes modificaciones a lo largo de las tres décadas posteriores.

12 La estructura básica engloba las instituciones sociales formales e informales que reparten las cargas y los beneficios de la cooperación social (Rawls 1996, 2002, 2002b).

13 Una sociedad así constituye un bien de varias maneras distinguibles entre sí. No voy a entrar en dicha distinción que resulta algo compleja, puede encontrarse una discusión en profundidad de la misma en Rawls (1996) o, de forma algo más introductoria, en Rawls (2002). 
pendientes de las doctrinas comprehensivas existentes. Por independencia se entiende que su aceptación no debe presuponer la aceptación de ninguna doctrina comprehensiva particular. En una situación ideal todas las doctrinas comprehensivas aceptarán las ideas del bien como integrantes de la propia doctrina. No obstante, eso no quiere decir que lo sean realmente; en realidad dichas ideas del bien son independientes de doctrinas comprehensivas particulares (Rawls 1996, 2002, 2002b).

La idea es más sencilla de lo que pudiera parecer; veámoslo con un ejemplo. La concepción política de la justicia que estamos manejando aquí comprende que todos los miembros de la sociedad son libres e iguales. Esta es, no cabe duda, una concepción de la persona que es hija del liberalismo. Sin embargo, puede ser presentada de forma independiente del liberalismo comprehensivo de Kant o Mill o de cualquier otra doctrina por el estilo y, a su vez, puede ser asumida como propia por cualquier doctrina que sea razonable. El ciudadano Mill, por ejemplo, que alberga una doctrina plenamente comprehensiva de corte liberal, podría sostener que él es liberal y que, por tanto, cree firmemente que todos los seres humanos deben ser libres e iguales. A su vez, el ciudadano Pedro, que alberga una doctrina comprehensiva plena de corte cristiano, podría creer firmemente en que todos los seres humanos deben ser libres e iguales porque ese es el auténtico mensaje de Cristo, y así sucesivamente. Eso no significa que la concepción política sea liberal, ni cristiana, es independiente de doctrinas comprehensivas, se trata de una forma de ética sin moral ${ }^{14}$ (Arnsperger y Van Parijs 2002).

Cuando las diferentes doctrinas comprehensivas alcanzan un consenso de este tipo en torno a una concepción política de la justicia, se logra lo que Rawls (1996, 2002, 2002b) denomina un consenso entrecruzado de doctrinas comprehensivas razonables. Unas cuantas precisiones resultan adecuadas en este punto. La diferencia entre una concepción política y una doctrina comprehensiva es una cuestión de alcance. La concepción política afecta sólo a las instituciones básicas formales e informales de la sociedad que regulan el reparto equitativo de las cargas y beneficios de la cooperación. Es en este sentido preciso en el que utilizamos el adjetivo «política» para referirnos a tal concepción; es política, no metafísica. Las doctrinas comprehensivas van mucho más allá y, como vimos, afectan a la vida entera de las personas. La construcción de un consenso entrecruzado no tiene nada que ver con una negociación política entre personas que albergan distintas doctrinas comprehensivas y buscan algún punto intermedio entre todas ellas. Enlazando con una discusión anterior, la concepción política tampoco es neutral en este sentido. El mecanismo es justo el contrario, primero elaboramos una concepción política que sea equitativa y, después, serán las diferentes doctrinas comprehensivas

14 Esto no quita, sin embargo, que reconozcamos que, evidentemente, el liberalismo comprehensivo gozará en una sociedad así de una cierta preeminencia entre las doctrinas comprehensivas abrazadas por los ciudadanos. 
las que tendrán que adaptarse a la misma si son razonables. Como se dijo más arriba, normalmente las personas no albergan doctrinas plenamente comprehensivas, cosa que facilita el consenso. De hecho, cuando encontramos a alguien que sigue a rajatabla los principios de alguna doctrina comprehensiva particular no podemos evitar una cierta sonrisa maliciosa al notar que nos encontramos ante un personaje peculiar. Normalmente las personas albergan creencias y deseos procedentes de doctrinas comprehensivas diferentes y que, en muchos casos, resultan bastante inconsistentes y contradictorios entre sí. Personas de este tipo es más fácil que asuman los principios de una sociedad política justa. Como vimos, las personas valoran dichos principios como un bien social de primera magnitud. Si en un momento dado encontrasen que alguno de esos principios es contradictorio con alguna de sus creencias, resulta mucho más probable que renuncien a su creencia en lugar de renegar del principio (Rawls 1996).

En síntesis, el Estado puede y debe promover todas aquellas ideas del bien que sean necesarias para asegurar la justicia de la sociedad. La única restricción a la que debe someterse en ese ejercicio es, nuevamente, la de la primacía de lo correcto, de lo justo, sobre lo bueno, a saber, el Estado debe abstenerse de promover ideas del bien con la intención de favorecer o perjudicar a una determinada doctrina comprehensiva. Insisto en la cuestión de la intención porque es la idea clave aquí. El Estado debe promover una determinada idea del bien si es un medio necesario para alcanzar o estabilizar la justicia de la sociedad pero no puede hacerlo con el propósito de beneficiar o perjudicar a tal o cual doctrina. Como vimos, la neutralidad se reduce en este punto a neutralidad de propósitos, no se trata de buscar la neutralidad de consecuencias que sería imposible y, en muchos casos, indeseable (Rawls 1996, 2002).

\section{Las virtudes cívicas}

La virtud cívica constituye un caso particular de la discusión anterior pero, dada la relevancia de este tema para el presente trabajo, la abordaré por separado aquí. Pese a que el liberalismo político ${ }^{15}$ es neutral en el sentido especificado, ello no le impide afirmar la superioridad de determinadas formas de carácter moral y estimular determinadas virtudes políticas (Rawls 1996, 2002). Una teoría liberal de la justicia como la de Rawls incluye determinadas virtudes políticas de primera magnitud como la tolerancia, la razonabilidad o el sentido de la justicia. Una concepción política liberal no supone a los ciudadanos únicamente como racionales sino también como razonables. Los ciudadanos no se limitan a cumplir con lo establecido por los principios rectores de la cooperación social por un simple cálculo estratégico (para evitar

15 Nuevamente, el adjetivo «político» distingue (limita el alcance) al liberalismo de Rawls del liberalismo comprehensivo de Kant o Mill. 
las sanciones derivadas del incumplimiento, por ejemplo). El sentido de la justicia de los ciudadanos no se reduce a suponerlos capaces de comprender lo que la justicia requiere sino que incluye el actuar motivados para la realización de dichos requerimientos.

Como se dijo, el normal funcionamiento de las instituciones de una sociedad libre influye sobre las doctrinas comprehensivas (sobre las creencias y deseos, al fin y al cabo) de las personas que tienden a tornarse razonables si no lo eran. Obviamente, este hecho incluye el desarrollo de virtudes políticas como las mencionadas. Volvemos a toparnos en este punto con la cuestión de la neutralidad. Vemos que el Estado no es neutral en cuanto a las consecuencias de su actuación. Tal cosa sería imposible en buena medida y, además, en casos como éste también sería indeseable. En efecto, que el normal funcionamiento de las instituciones tenga como subproducto la creación de virtud cívica resulta vital para la estabilidad de una sociedad libre.

Pero lo que el Estado puede y debe hacer en materia de virtud no se agota aquí. Existen muchas otras virtudes que son necesarias para alcanzar o estabilizar una sociedad justa y que no son promovidas (o no lo son en suficiente medida) por el normal funcionamiento institucional. Puede incluso, si nos atenemos a la lógica subyacente al ejemplo de la sardana, que el normal funcionamiento institucional debilite ciertas virtudes importantes para la justicia o, de modo más general, importantes para otros bienes sociales que no son la justicia pero que también son importantes. Por ejemplo, la proliferación sin límite de estilos de vida diferentes e incluso antagónicos, siendo positiva en tanto que manifestación de la libertad individual de los ciudadanos, podría deteriorar las bases de la cohesión social (Van Parijs 1993). En respuesta a este tipo de cuestiones diremos que el Estado debe promover todas aquellas virtudes necesarias para alcanzar o estabilizar la justicia de la sociedad ${ }^{16}$.

Es necesario precisar la anterior afirmación. Se sostiene que el Estado (si es auténticamente liberal igualitarista) «debe» promover dichas virtudes, no que simplemente «tenga la opción» de hacerlo. Tal y como se apuntó más arriba, desde posturas comunitaristas, marxistas y republicanas suele acusarse al liberalismo igualitarista de sucumbir ante el vicio, dado que el principio de neutralidad le impide promover las virtudes necesarias para dotar de estabilidad a sus ideales de justicia. En la misma línea, acostumbra también a argumentarse que los liberales igualitaristas, presos entre cuernos de un dilema, no tienen más remedio que cometer violaciones puntuales del principio de neutralidad en aras de poder salvar al menos una parte de su ideal de justicia ${ }^{17}$. Existen elementos suficientes para responder a esas críticas. No se trata

16 Arnsperger y Van Parijs (2002); Kymlicka (2004); Patten (2004); Rawls (1996, 2002); Van Parijs (1993, 1996).

17 En este mismo sentido, suele acusarse a las teorías de la justicia liberales de ser ideales en el sentido negativo de desconectadas de la realidad e inviables. Véase, por ejemplo, Bertomeu y Domènech (2005). 
de que el Estado pueda, como mal menor, promover algunas virtudes si no hay más remedio. El Estado está normativamente obligado a promover todas aquellas virtudes necesarias para alcanzar o estabilizar la justicia de la sociedad.

En segundo lugar, el Estado sólo debe fijar un límite en la promoción de la virtud. A estas alturas ya debería estar claro cuál es ese límite, se trata de la línea roja marcada por la prioridad de lo correcto sobre lo bueno. Otra vez, no podemos introducir determinadas virtudes en la concepción política porque pertenecen a tal o cual doctrina comprehensiva que nosotros apoyamos, debemos hacerlo porque, y sólo porque, resultan necesarias para alcanzar o dotar de estabilidad a la justicia de la sociedad. En este sentido, las virtudes deben ser, como la concepción política en su conjunto, independientes de las distintas doctrinas en el sentido que he especificado más arriba, a saber, debe tratarse de virtudes a las que ciudadanos razonables que albergan doctrinas comprehensivas razonables podrían prestar su apoyo ${ }^{18}$.

Y una tercera aclaración, tal y como se ha sostenido en la introducción, la virtud es instrumental para la justicia, no constitutiva de la misma (Kymlicka 2004; Patten 2004; Van Parijs 1996). Esta afirmación necesita a su vez de posteriores aclaraciones. La virtud, un determinado tipo de motivaciones, no es parte constitutiva de la justicia, no nos dice nada sobre lo que la justicia es (Kymlicka 2004; Patten 2004; Van Parijs 1996). Lo que dictamina que una sociedad sea justa es que se cumpla lo estipulado por unos determinados principios de justicia (los dos principios de la justicia como equidad rawlsiana o el maximín de la libertad real de Van Parijs, por ejemplo). Los principios de justicia que deban regir la cooperación social se encuentran inscritos, obviamente, dentro de la concepción política. La concepción política, no obstante, incluye, tal y como hemos visto, muchas más cosas, entre ellas virtudes, ideas del bien y una concepción de la persona. Esto no significa, sin embargo, que todas esas cosas constituyan la justicia, se incluyen en la concepción política simplemente para dotar de estabilidad a la misma ${ }^{19}$. Esto no implica, obviamente, que la virtud cívica no sea importante, su importancia resulta vital en

18 Nótese que digo que podrían hacerlo, no que lo hagan realmente, se trata de un supuesto hipotético no empírico. Sobre el uso de supuestos hipotéticos en la elaboración de una teoría de la justicia véase Rawls (1990, 1996, 2002, 2002b) o Rawls en Habermas y Rawls (1998).

19 Rawls nunca fue claro a este respecto. Él incluye ideas del bien y virtudes en la concepción política, del mismo modo que incluye las libertades políticas iguales y la democracia. Sin embargo, afirma que tales cosas, las libertades políticas iguales, por ejemplo, tienen una importancia mucho menor que otras libertades «civiles» o «modernas». En este sentido «el papel de de las libertades políticas quizá no sea sino fundamentalmente instrumental para la concepción de las demás libertades» (Rawls 1996, p. 336). Entiendo que el «quizá» denota la voluntad de no entrar en cuestiones en las que, dada su manera de plantear el problema, no necesitaba entrar. Sin embargo, la elaboración del problema resulta absolutamente nítida en el resto de la tradición liberal como en las formulaciones citadas de Van Parijs (1996) o Patten (2004) con las que me encuentro de acuerdo. 
una sociedad libre. Simplemente se dice que no es constitutiva de la justicia, pero reconocer lo anterior en modo alguno significa poner en duda que la virtud cívica representa un instrumento indispensable para realización práctica de la justicia (Kymlicka 2004; Patten 2004; Van Parijs 1996). Que la virtud no es constitutiva de la justicia es una tesis teórica o definicional. Que la virtud es un instrumento indispensable para la realización práctica de la justicia es una tesis empírica.

\section{Conclusiones}

Los críticos del liberalismo igualitario suelen sostener la falsedad de la tesis kantiana según la cual bienes sociales como la justicia de la sociedad son alcanzables y sostenibles sin virtud cívica y no deben depender de ésta. A su vez acostumbran a acusar al liberalismo igualitarista de abrazar dicha tesis lo que les lleva a concluir que los fines liberales igualitaristas como la justicia social son inalcanzables y/o inestables.

En el presente trabajo se ha partido de asumir que, efectivamente, la tesis de Kant es falsa. No obstante, se ha tratado de argumentar que el liberalismo igualitarista no asume dicha tesis y que, por tanto, los críticos andan desencaminados.

A lo largo de estas páginas se han presentado los conceptos rawlsianos de pluralismo razonable, de consenso entrecruzado entre doctrinas comprehensivas razonables y de neutralidad del Estado, y se ha tratado de aclarar cuál es el papel de la virtud cívica dentro de ese entramado teórico.

Se ha sostenido que el Estado liberal igualitarista está obligado a promover todas aquellas virtudes que sean necesarias para alcanzar y estabilizar la justicia de la sociedad con el único límite del respeto a la prioridad de lo correcto sobre lo bueno. Desde el liberalismo igualitarista no se concibe a la virtud cívica como constitutiva de la justicia de la sociedad sino que se la defiende como instrumento necesario para la realización práctica de la misma.

\section{BIBLIOGRAFÍA}

Arnsperger, C. y VAn PARIJs, P. (2002): Ética económica y social. Teorías de la sociedad justa, Barcelona: Paidós.

Berlin, I. (2004): Sobre la libertad, Madrid, Alianza Editorial.

Bertomeu, M. J., y Domènech, A. (2005): «El republicanismo y la crisis del rawlsismo metodológico (Nota sobre método y sustancia normativa en el debate republicano)», en Bertomeu, M. J., De Francisco, A. y Domènech, A. (comp): Republicanismo y democracia, Madrid, Miño y Dávila.

Cohen, G. (2001): Si eres igualitarista, ¿como es que eres tan rico?, Barcelona, Paidós. 
Cohen, J. (2001): «Democracia y libertad», en ElSTER, J. (comp.) La democracia deliberativa, Barcelona, Gedisa.

DOMÈNECH, A. (1989): De la ética a la política. De la razón erótica a la razón inerte, Barcelona, Crítica.

— (1996): «Ética y economía de bienestar: una panorámica», en Osvaldo GUARIGLIA (ed.): Cuestiones morales, Madrid, Trotta, pp. 191-222.

- (1998): «Ocho desiderata metodológicos de las teorías sociales normativas», en Isegoría, n. ${ }^{\circ} 18, \mathrm{pp} .115-141$.

- (2003): «Democracia, virtud y propiedad», en ArTetA, A., GarcíA, E. y Máiz, R., Teoría política: poder, moral y democracia, Madrid, Alianza.

- (2004): El eclipse de la fraternidad. Una revisión republicana de la tradición socialista, Barcelona, Crítica.

Habermas, J. (2001): Facticidad y validez, Madrid, Trotta.

- y Rawls, J. (1998): Debate sobre el liberalismo político, Barcelona, Paidós.

KANT, I. ([1795] 1985): La paz perpetua, Madrid, Tecnos.

KymlickA, W. (2004): «Igualitarismo liberal y republicanismo cívico: ¿amigos o enemigos?», en Ovejero, F., Martí, J. L. y Gargarella, R. (comp.) (2004): Nuevas ideas republicanas. Autogobierno y libertad, Barcelona, Paidós.

NoguerA, J. A. (2003): «Rawlsianos, marxistas y santos: sobre el socialismo igualitarista de G.A. Cohen» (texto inédito; presentado en el IV Congrés Català de Sociologia, Reus, abril de 2003). Consultable en: http://selene.uab.es/_cs_gr_saps/ catala/xgeneral2.htm

Ovejero, F., Martí, J. L. y Gargarella, R. (2004): «Introducción», en Ovejero, F., Martí, J. L. y Gargarella, R. (2004): Nuevas ideas republicanas. Autogobierno y libertad, Barcelona, Paidós.

PATten, A. (2004): «La crítica republicana al liberalismo», en OveJERo, F., MARTí, J. L. y Gargarella, R. (comp.): Nuevas ideas republicanas. Autogobierno y libertad, Barcelona, Paidós.

PetTit, P. (1999): Republicanismo. Una teoría sobre la libertad y el gobierno, Barcelona, Paidós.

- (2004): «Liberalismo y republicanismo», en OveJero, F., MARTí, J. L. y Gargarella, R. (comp.) (2004): Nuevas ideas republicanas. Autogobierno y libertad, Barcelona: Paidós.

Rawls, J. (1979): Teoría de la justicia, México, Fondo de cultura económica.

- (1990): Sobre las libertades, Barcelona, Paidós.

- (1996): El liberalismo político, Barcelona, Crítica.

- (2002): La justicia como equidad: una reformulación, Barcelona, Paidós.

- (2002b): «Justicia como imparcialidad: política, no metafísica», en GómEz, C. (2002): Doce textos fundamentales de la ética del siglo XX, Madrid, Alianza.

SANDEL, M. (2004): «La república procedimental y el yo desvinculado», en OvEJERO, F.; Martí, J. L. y Gargarella, R. (comp.) (2004): Nuevas ideas republicanas. Autogobierno y libertad, Barcelona: Paidós.

SEN, A. (2000): Desarrollo y libertad, Barcelona, Planeta.

Sunstein, C. (2004): «Más allá del resurgimiento republicano», en Ovejero, F., Martí, J. L. y Gargarella, R. (comp.) (2004): Nuevas ideas republicanas. Autogobierno y libertad, Barcelona, Paidós. 
TenA, J. (2008): «Una propuesta de definición del concepto de virtud cívica», en prensa.

VAN PARIJS (1993): ¿Qué es una sociedad justa? Introducción a la práctica de la filosofía política, Barcelona, Ariel.

- (1996): Libertad real para todos. Qué puede justificar el capitalismo. Si hay algo que pueda hacerlo, Barcelona, Paidós. 